\title{
A Research on Constructing College Teaching Mode Based on IT Multidimensional Interaction
}

\author{
Fu Zhentong ${ }^{1, a}$ \\ ${ }^{1}$ Daqing Normal University, Daqing, 163712,China \\ afuzhentong2013@yeah.net
}

Keywords: IT multidimensional interaction, College teaching mode, innovation, SPSS

\begin{abstract}
With the implementation of the new educational reform, many universities begin to explore new teaching modes. teaching is the foundation course and the important content of teaching reform. The new teaching model focuses on the innovation of teaching methods of teachers and innovation of thinking of students. In this context, this paper proposes a multidimensional interactive innovation of College teaching mode.
\end{abstract}

\section{Introduction}

Teaching is the basic language teaching. If the teaching method follows the traditional teaching mode, the courses are boring and the atmosphere of classroom are inactive, and student's way of thinking cannot be renewed, as a result, students cannot learn course very well by relying on mechanical memorizing model. How to liven the atmosphere of classroom, innovate the teaching methods and develop students' thinking ability is the new focus of the education reform. This paper proposes a new method of teaching - - multidimensional interactive teaching mode. This mode advocates the interaction of teachers and students.

\section{The contrast of traditional teaching mode and interactive teaching mode}

College teaching is a basic teaching. The traditional teaching mode focuses on the mastery of knowledge rather than the application of the knowledge. College learning should focus on the application of the students' knowledge of , especially the knowledge closely related to their major. In order to achieve this effect, a kind of interactive session needs to be added into the process of learning. Students can master and use the linguistic tool---------- in the process of interactive learning and expand their thinking and cultivate their ability to apply [1].

\section{Multidimensional interactive college teaching mode}

The traditional teaching mode has been unable to meet the requirements of the new education reform. New college teaching has added a lot of interactive sessions. In interactive teaching mode, students can better improve their ability of learning and applying. Multidimensional teaching mode consists of six parts [2]. The most important parts are the classroom topics interaction and video interaction after class. In interactive sessions of the classroom topics, students prepare in advance the topic to be discussed in class, the teacher organizes the topic carefully, and in this way, students can better understand and learn more about the topic. In the information-gathering process, students can broaden their vision and innovate their thinking of . In the discussion process in class, teachers can correct students' pronunciation and grammar errors. After class, students can communicate with each other through video interaction and network, browse the video in class and consolidate their knowledge of language online..

\section{Mathematical multidimensional interactive College teaching mode based on IT}

According to the principle of interactive information technology, how to allocate the multidimensional interactive teaching content is the main content of this study. First, it assumes 
that there are four basic elements: classroom topic interactions, video interactions after class, corners and interaction of international students [2]. It assumes every element as $\mathrm{H}, \mathrm{J}, \mathrm{K}, \mathrm{L}$. Assuming that there are four students, and the time of every student completes the content is shown in table 1.

Table 1 . The timetable of the completion of teaching contents

\begin{tabular}{c|c|c|c|c}
\hline $\begin{array}{c}\text { Contents } \\
\text { Students }\end{array}$ & $\boldsymbol{H}$ & $\boldsymbol{J}$ & $\boldsymbol{K}$ & $\boldsymbol{L}$ \\
\hline 1 & 21 & 18 & 21 & 29 \\
2 & 19 & 25 & 28 & 21 \\
3 & 27 & 17 & 14 & 19 \\
4 & 16 & 21 & 25 & 18 \\
\hline
\end{tabular}

We can use the assignments principle of information interactive technology to assume $\mathrm{i}$ students and i teaching contents and introduce i2 0-1 variables for the reasonable and optimal allocation of multi-dimensional interactive teaching content.

$$
Y_{e f}= \begin{cases}1 & e \text {-th student can complete the } \mathrm{f}-\text { th teachin } \mathrm{g} \text { content } \\ 0 & e \text {-th student can't complete the } \mathrm{f} \text { - th teachin g content }\end{cases}
$$

$$
\begin{aligned}
& \text { Min } \mathrm{X}=\sum_{\mathrm{e}=1}^{\mathrm{m}} \sum_{\mathrm{f}=1}^{\mathrm{m}} \mathrm{k}_{\text {ef }} \mathrm{y}_{\text {ef }} \\
& \sum_{e=1}^{m} y_{e f}=1 \quad f=1,2 \cdots v \\
& \sum_{f=1}^{m} y_{e f}=1 \quad e=1,2 \cdots v \\
& y_{e f}=0 \text { or } 1 \quad e, f=1,2 \cdots v
\end{aligned}
$$

$$
y=\left(y_{e f}\right)_{v \times v}=\left[\begin{array}{cccc}
y_{11} & y_{12} & \cdots & x_{1 i} \\
y_{21} & y_{22} & \cdots & x_{2 i} \\
\cdots & & & \\
y_{i 1} & y_{i 2} & \cdots & x_{i i}
\end{array}\right]
$$

Assume that the constraint is that a student can and only can complete a course. The mathematical model can be expressed using the following matrix as:

According to the parameters, we can use mathematical model to optimize the multidimensional interaction of college teaching content:

$y_{e f}=\left\{\begin{array}{l}1 \mathrm{e} \text { - th student completes the } \mathrm{f} \text { - th teaching content } \\ 0 \text { e - th student completes the } \mathrm{f} \text { - th teaching content }\end{array}(e, f=1,2, \cdots, 4)\right.$

So, the mathematical model of the problem is:

$$
\begin{aligned}
& \text { Minx }=\sum_{e=1}^{4} \sum_{f=1}^{4} k_{e f} y_{e f}=21 y_{11}+18 y_{12}+\cdots+25 y_{43}+18 y_{44} \\
& \begin{cases}\sum_{e=1}^{4} y_{e f}=1 \quad f=1,2 \cdots 3 \\
\sum_{f=1}^{4} y_{e f}=1 \quad e=1,2 \cdots 3 \\
y_{e f}=0 \text { or } 1 \quad e, f=1,2 \cdots 3\end{cases}
\end{aligned}
$$

With the passage of time, $\mathrm{N}$ is gradually increased. As mentioned previously, current policy, study status and potential curve move up. At this time, when personality thought potential function of one aspects reach 1 first, and it overcomes the relationship of original variable index between the education. That can be more comprehensive in the education. It is objective and reasonable to evaluate process to determine the weight, and it overcomes the defect artificial weight determined of other evaluation methods [3].

If $\mu^{\mathrm{A}} \tau^{A} \leq \mu^{M} \bar{\tau}^{\mathrm{M}}$, give a group of industry discretionarily $\mathrm{h}$ and g, and $\mathrm{h} \leq \tilde{H}, \mathrm{~g} \leq \tilde{H}$. On the whole, given thought condition index $\mathrm{h}$ and $\mathrm{g}$, if $\mathrm{p}$ and $\mathrm{g}$ are less than or equal to $\rho^{\mathrm{g}}$ and $\tau^{\mathrm{g}}$ (one of them must be strictly less than), then we say that state of mind " $\mathrm{g}$ " are better than 
" $h$ ". In the analysis process of individual student's condition, distribution density function will be obtained from situation of all kinds of students by coupling factor. At the same time, the probability of the individual characteristics should be known to be convenient to establish an appropriate criterion rules. The student individual critical learning potential curve of its specific constituting are as below.

It showed $\rho^{\mathrm{h}}$ influence on students' individual critical learning potential curve which is also named $\Omega^{\mathrm{h}}$ ( $\mathrm{r} ; \tilde{\mathrm{N}}^{\mathrm{h}}$,such as bad information spreads into the college students' view. It creates opportunities for the college education, which it is based on the information technology multidimensional interaction for course teaching of college students .It can effectively avoid bad effect and negative effect on college students. Three imaginary curves are given in the diagram:

$$
\rho^{1}=0.90>\rho^{2}=0.75>\rho^{3}=0.20
$$

All other parameters are constant, and set to:

$$
\rho^{1}=0.90>\rho^{2}=0.75>\rho^{3}=0.20
$$

All other parameters are constant, and set to the following formula:

$$
\mu^{\mathrm{A}}=0.5, \mu^{1}=\mu^{2}=0.1, \mu^{3}=0.3
$$

$\tau^{\mathrm{A}}=0.8, \tau^{\mathrm{h}}=1$, for all the $\mathrm{h}$, it was established, $\mathrm{c}^{\mathrm{A}}=0.5$

In the process of monomer composition analysis among all the students, it makes standardiza tion of processing to each student's index, and makes the students in different conditions (differ ent measures index) into the same measure of indicators. It eliminates difference of student's le vel, and makes great comparability in a student's situation. Industry3 is the industry of highest 1 evel, and industry 1's level is minimum. We are very easy to prove that these parameters are at $\widetilde{\mathrm{H}}=2$, it meets the following formula: $\mu^{\mathrm{M}}\left(\tau^{A}+\bar{\tau}^{M}\right) /\left(\tau^{A}+\tau^{h}\right)<\rho^{h}, h=1,2, \cdots, \tilde{H}$. And the con dition of $\mu^{\mathrm{M}}\left(\tau^{A}+\bar{\tau}^{M}\right) /\left(\tau^{A}+\tau^{h}\right) \geq \rho^{h} h=\tilde{H}+1, \cdots, H \quad(1 \leq \tilde{\mathrm{H}} \leq H$.

In the picture, we described the three related critical curve, and then get the following critical value:

$$
\begin{aligned}
& \tilde{N}^{1}=0.88<\tilde{N}^{2}=4.36, \tilde{f}^{1}=0.40<\tilde{f}^{2}=1.40 \\
& \tilde{r}^{1}=0.32<\tilde{r}^{2}=1.10 \text {, and } \tilde{\theta}^{1}=5.5>\tilde{\theta}^{2}=1.90>\tilde{\theta}^{3}=0.25
\end{aligned}
$$

Therefore, when the student individual thought factor achieved minimum threshold ( $\tilde{N}^{1}=0.88$ ), the whole teaching effect 1 will reach to 1 at the maximum of $\tilde{r}^{1}=0.32$. Thus it effectively cultivate students' consciousness of independent spirit, and students are encouraged to ask the question when they accept education [4].

\section{Research on the effect of college teaching mode}

This paper investigates, gathers statistics and analyzes the teaching effect of a multidimensional interactive teaching mode. Then, it inputs statistical data into SPSS parameter setting module. We can get the mean, variance, and significance level from the computational analysis module. 
Table 2. The statistical table of teaching contents

\begin{tabular}{c|c|c|c|c|c}
\hline Classification & $\begin{array}{c}\text { Interaction average } \\
\text { value }\end{array}$ & $\begin{array}{c}\text { Non-interaction } \\
\text { average value }\end{array}$ & $\begin{array}{c}\text { Interaction } \\
\text { standard } \\
\text { deviation }\end{array}$ & $\begin{array}{c}\text { Non-interaction } \\
\text { standard } \\
\text { deviation }\end{array}$ & Significant level \\
\hline Topic & 4.8 & 4.1 & 0.84 & 0.82 & $>0.055$ \\
Video & 4.5 & 3.9 & 0.81 & 0.78 & $>0.055$ \\
$\begin{array}{c}\text { International } \\
\text { students }\end{array}$ & 3.1 & 0.5 & 1.21 & 1.23 & $<0.055$ \\
Grade difference & 2.2 & 1.2 & 1.25 & 1.27 & $<0.055$ \\
corner & 2.5 & 0.1 & 1.31 & 1.35 & $<0.055$ \\
\hline
\end{tabular}

From the statistical analysis of the teaching effectiveness, we can see that the evaluation scores of interaction of topics in class and video interaction are the highest. The interactive sessions are the most in the two contents. The uses of knowledge are more. In the stage of topic discussion in class, the listening and speaking ability of students get a good play and the grammatical errors and pronunciations can be corrected timely. In the stage of summary and writing, students' writing ability can be improved. Students can improve their speaking and writing ability through these two stages [5].

\section{Conclusion}

This paper puts forward a new multidimensional interactive teaching mode by using the information interactive technology. The first part compares two teaching models: traditional teaching mode and interactive teaching mode. Through the comparison, we can get that the traditional teaching mode cannot meet the needs of the new educational reform. The second part elaborates the content and form of multidimensional interactive college teaching mode. The third part establishes mathematical model of the distribution of college multidimensional interactive teaching content through the principle of information interactive technology. It also gives the matrix form of teaching task allocation by using specific examples. Finally, it analyzes the effect of multi-dimensional interactive teaching through using the statistical analysis software SPSS. It gets the mean, variance and significance level of teaching effect. By optimizing the parameters and teaching effect, multidimensional interactive distribution of teaching effect provides a theoretical basis for the exploration of multidimensional interactive teaching mode.

\section{References}

[1] Lynda A Anderson, Patricia A Sharpe, "Improving patient and provider communication: A synthesis and review of communication interventions", Patient Education and Counseling, Vol. 17, No. 2, pp. 99-134, 2006.

[2] Faridah Pawan, "Content-area teachers and scaffolded instruction for language learners", Teaching and Teacher Education, Vol. 24, No. 6, pp. 1450-1462, 2008.

[3] Yin Xiuqing, "Research of Key Technologies on Online Teaching System Based on P2P Streaming", JDCTA, Vol. 7, No. 2, pp. 525 - 532, 2013.

[4] Ian Pownall, "Student identity and group teaching as factors shaping intention to attend a class", The International Journal of Management Education, Vol. 10, No. 2, pp. 61-74, 2012.

[5] Yanli Liang, "Research of Multimedia Interactive Teaching Evaluation System under Network Environment", IJACT, Vol. 5, No. 2, pp. 451 - 459, 2013. 